\title{
Kanglaite stimulates anticancer immune responses and inhibits HepG2 cell transplantation-induced tumor growth
}

\author{
XINLI HUANG，JIANJIE QIN and SEN LU \\ Center of Liver Transplantation, The First Affiliated Hospital of Nanjing Medical University, \\ Key Laboratory of Living Donor Liver Transplantation, Ministry of Health, Nanjing 210029, P.R. China \\ Received December 9, 2013; Accepted April 25, 2014
}

DOI: $10.3892 / \mathrm{mmr} .2014 .2479$

\begin{abstract}
Previous studies revealed that Kanglaite (KLT) exhibits antitumor and immunomodulatory activities. In the present study, we show that KLT treatment stimulated the immune response by increasing the number of $\mathrm{T}$ cells and natural killer (NK) cells in the blood of hepatocellular carcinoma (HCC) patients. Experiments in tumor-bearing mice were further designed in order to explore the effects of KLT on the immune system and the underlying molecular mechanisms. The results showed that KLT improves the tumor cell transplantation-induced reduction in the serum level of the cytokines IFN- $\gamma$ and IL-2, and rescues the levels of $\mathrm{CD}^{+}$ $\mathrm{T}$ cells in host mice. These events enhanced the cytotoxic activities of natural killer and $\mathrm{CD} 8^{+} \mathrm{T}$ cells against the hepatic HepG2 cancer cells. KLT administration further increased the mRNA level of certain nuclear factor $\kappa \mathrm{B}(\mathrm{NF}-\kappa \mathrm{B})$-responsive genes in $\mathrm{CD}^{+}$cells. The chromatin immunoprecipitation assay showed that KLT increases the association of the $\mathrm{NF}-\kappa \mathrm{B}$ p65 subunit to the promoter regions of interleukin (IL)-2- and B-cell lymphoma (Bcl)-2-encoding genes in $\mathrm{CD}^{+} \mathrm{T}$ cells. Our study demonstrated that KLT is the main active ingredient of coix seed exhibiting anticancer and immunomodulatory properties. Induction of $\mathrm{NF}-\kappa \mathrm{B}-$ mediated gene transcription in $\mathrm{CD}^{+} \mathrm{T}$ cells is involved in the immunomodulatory activity of KLT.
\end{abstract}

\section{Introduction}

Hepatocellular carcinoma (HCC) is the fifth most prevalent malignant tumor in men worldwide and the second most frequent cause of cancer-related mortality (1). Although surgical resection and liver transplantation are the main

Correspondence to: Dr Sen Lu, Center of Liver Transplantation, The First Affiliated Hospital of Nanjing Medical University, Key Laboratory of Living Donor Liver Transplantation, Ministry of Health, 300 Guangzhou Rd, Nanjing 210029, P.R. China E-mail: lusen2013@126.com

Key words: Kanglaite, anticancer, hepatocellular carcinoma, immune response modalities of curative treatment for $\mathrm{HCC}$, most patients are at the late stages of the disease, when curative treatment is not feasible and the outcome is likely to be poor (2). Certain agents such as sorafenib and cisplatin have been approved for chemotherapeutic treatment of HCC, but their use is associated with limited survival, due to the resistance of HCC cells to these agents and their multiple toxic effects $(3,4)$. Therefore, it is important to identify new compounds with improved effectiveness and lower toxicity, in order to provide a wide range of clinical options for HCC patients.

Immunosuppression can be clearly detected in both cancer patients and tumor-bearing animals (5). During hepatocyte carcinogenesis, numerous immune tolerogenic factors induced by virus infection or chronic inflammatory response may accumulate, which facilitates an aggressive and effective counterattack against the anti-HCC immune responses of the host (6). For example, the frequencies of myeloid dendritic cells in HCC patients are reduced compared with their normal counterparts. This event impairs production of IL-12 and limits the allostimulatory activities of dendritic cells (7). Decreased numbers of circulating natural killer (NK) cells and their cytotoxic activities against $\mathrm{HCC}$ cells have also been described in HCC patients $(8,9)$. Notably, some agents targeting specific molecules have exhibited off-target effects on immune cells, including T cells, NK cells, monocytes and dendritic cells, in addition to their direct effects on tumor cells. Previous studies have demonstrated that sorafenib inhibits the function of NK cells, rendering the host more susceptible to tumor growth and metastasis $(10,11)$. Overall, these studies suggest that stimulating anti-HCC immunity may be a promising alternative strategy for the treatment of HCC.

Kanglaite (KLT) is an oily substance extracted from the plant species Coix lacryma-jobi (family, Poaceae). There is some evidence that medical use of coix seed and its extracts is beneficial in the treatment of cancer metastasis, hypertension, arthritis, asthma and immunological disorders (12). KLT was clinically used in China and significantly improved the lifespan and quality of life of patients when combined with chemotherapy, radiotherapy or surgery (13). A number of studies showed that KLT principally blocks the G2pM phase of the cell cycle, thereby reducing the mitotic division rates and inhibiting the proliferation of tumor cells, while it can also activate pro-apoptotic factors, leading to apoptosis (12). A recent study in mice with Lewis lung carcinoma further demonstrated that KLT 
exhibits antitumor activity in vivo, via its immunomodulatory effects (14). The nuclear factor $\kappa \mathrm{B}(\mathrm{NF}-\kappa \mathrm{B})$ is an important regulator of transcription that controls the expression of various genes involved in the immune system, cancer and inflammatory functions $(15,16)$. KLT increases the interleukin (IL)-2 level in the supernatant of isolated splenocytes, and decreases the $\mathrm{NF}-\kappa \mathrm{B}$ level in the nucleus of lung tumor cells (14).

In this study, we firstly evaluated the effects of KLT treatment on the immune response of HCC patients. In addition, we used C57BL/6 mice transplanted with HepG2 cells to investigate the effects of KLT treatment on HCC. Specifically, we assessed the tumor growth inhibition rate, liver indexes, and the number of immune system cells in tumor-bearing mice, and explored the molecular mechanisms underlying the effects of KLT.

\section{Materials and methods}

Human blood samples. KLT was provided by Zhejiang Kanglaite Pharmaceutical Co., Ltd. (Hangzhou, China). Human blood samples of 10 patients with HCC (aged between 35 and 67, six male and four female) treated with KLT were obtained from The First Affiliated Hospital of Nanjing Medical University. The study protocol was approved by the Institutional Ethics Committee of The First Affiliated Hospital of the Nanjing Medical University.

Flow cytometric analysis (FACS). The percentages of NK cells, $\mathrm{CD}^{+}$and $\mathrm{CD}^{+} \mathrm{T}$ cells were measured by flow cytometry (BD FACSCalibur ${ }^{\mathrm{TM}}$ platform; BD Biosciences, Franklin Lakes, NJ, USA) as previously described (17). Briefly, purified CD4 ${ }^{+}$ and $\mathrm{CD}^{+} \mathrm{T}$ cells were fixed with cold $70 \%$ ethanol (stored at $-20^{\circ} \mathrm{C}$ ) for at least $2 \mathrm{~h}$ at $4^{\circ} \mathrm{C}$. The cells were resuspended and washed twice with phosphate-buffered saline (PBS) containing $20 \mathrm{mM}$ EDTA. Intercellular RNA was removed by incubating the samples with RNase A (Sigma-Aldrich, St. Louis, MO, $\mathrm{USA} ; 1 \mathrm{mg} / \mathrm{ml})$ at $37^{\circ} \mathrm{C}$ for at least $1 \mathrm{~h}$. Cells were then stained with propidium iodide $(30 \mu \mathrm{g} / \mathrm{ml})$ and cell cycle distribution was analyzed by FACS. The percentages of the cells were estimated relative to the percentage of the subG1 DNA content.

Enzyme-linked immunosorbent assay (ELISA). The production of the cytokines IL-2 and interferon (IFN)- $\gamma$ in the blood serum was measured by a standard sandwich ELISA assay. The assay was performed according to the instructions of the corresponding mouse IL-2 and IFN- $\gamma$ kits, purchased from R\&D Systems, Inc. (Minneapolis, MN, USA). Absorbance of the samples was measured on an ELISA microplate reader (Multiskan Ex; Thermo Labsystems Oy, Helsinki, Finland).

Nude mouse xenograft assay. Male nude BALB/c mice (6 weeks-old) were obtained from the Shanghai Experimental Animal Center (Chinese Academy of Sciences, Shanghai, China), and housed under pathogen-free conditions. All the animal-handling procedures were conducted in accordance with experimental animal guidelines established by the Experimental Animal Management Committee of Jiangsu Province. HepG2 cells were obtained from the Type Culture Collection of the Chinese Academy of Sciences (Shanghai, China). HepG2 cells were cultured in DMEM containing $10 \%$ fetal bovine serum, 100 units $/ \mathrm{ml}$ penicillin, $100 \mu \mathrm{g} / \mathrm{ml}$ streptomycin and $5.5 \mathrm{mM}$
D-glucose at $37^{\circ} \mathrm{C}$ with $5 \% \mathrm{CO}_{2}$. To induce tumor growth, $5 \times 10^{6}$ HepG2 cells $(200 \mu \mathrm{l})$ were subcutaneously injected into the right flank of the mice. When the tumor areas had reached $\sim 30 \mathrm{~mm}^{2}$ (at 4 days after inoculation), the mice were randomly assigned to four groups, with ten mice in each group. The positive control group received $5 \mathrm{mg} / \mathrm{kg}$ cisplatin (Sigma-Aldrich). The vehicle control group received $0.9 \%$ normal saline. The KLT groups received 6.25 (KLT low) and 12.5 (KLT high) $\mathrm{mg} / \mathrm{kg}$ KLT by intraperitoneal injection for 12 days. Tumor growth was assessed every 3 days by measuring the tumor area, calculated as $\mathrm{V}=1 \mathrm{w}$, where 1 is the length and $\mathrm{w}$ is the width. Then, all mice were sacrificed, and the tumors were immediately weighed.

Determination of blood indexes of liver function. Blood samples were collected in heparinized tubes from the mice prior to sacrifice, under diethyl ether anesthesia. Serum was prepared by centrifugation of the blood samples at 4,000 $\mathrm{x} g$ for $15 \mathrm{~min}$. Serum aspartate aminotransferase (AST) and alanine aminotransferase (ALT) levels were determined using an automatic biochemical analyzer (Sysmex Corp., Tokyo, Japan) according to the manufacturer's instructions.

Isolation of subsets of immune cells. Splenic cells were isolated from harvested mouse spleen tissue samples in a sterile environment. CD4 ${ }^{+} \mathrm{T}, \mathrm{CD} 8^{+} \mathrm{T}$ and $\mathrm{NK}$ cells were purified from single-cell suspensions of mouse splenocytes using a magnetic-activated cell sorting (MACS) system, the rat anti-mouse CD4, CD8, $\mathrm{CD} 49 \mathrm{~b}$, and the goat anti-rat IgG microbeads, purchased from BD Biosciences.

Cytotoxic activity determination. The cytotoxic activity of mouse $\mathrm{NK}$ and $\mathrm{CD}^{+} \mathrm{T}$ cells against HepG 2 cells was measured based on the activity of lactate dehydrogenase, which is released from damaged cells. For this purpose, we used the CytoTox $96^{\circledR}$ Non-Radioactive Cytotoxicity Assay kit (Promega BioSciences, inc., San Luis Obispo, CA, USA) according to the manufacturer's instructions.

Quantitative reverse transcription ( $q R T)-P C R$. Total RNA was isolated using the TRIzol reagent (Invitrogen, Carlsbad, CA, USA) following the manufacturer's instructions. Complementary (c)DNA was synthesized from $2 \mathrm{mg}$ RNA using the M-MLV reverse transcriptase (Promega, Madison, WI, USA) and an oligo(dT) primer, following the manufacturer's instructions. The levels of the mRNA encoding B-cell lymphoma (Bcl)-2, Bcl-xL and IL-2 were determined by qPCR on these cDNAs, using the TransStart SYBR green qPCR kit (Beijing TransGen Biotech Co., Ltd., Beijing, China) on a MyiQ thermocycler (Bio-Rad, Hercules, CA, USA). Each PCR reaction mixture $(20 \mathrm{ml})$ contained $10 \mathrm{ml}$ of 2 SYBR-Green Master mix and $7 \mathrm{ml}$ of the forward and reverse primers $(5 \mathrm{nM})$. The reactions were incubated for $10 \mathrm{~min}$ at $95^{\circ} \mathrm{C}$, followed by 45 cycles of incubation at $95^{\circ} \mathrm{C}$ for $15 \mathrm{sec}, 60^{\circ} \mathrm{C}$ for $15 \mathrm{sec}$ and $72^{\circ} \mathrm{C}$ for $15 \mathrm{sec}$. The expression levels of the target genes were normalized to that of the glyceraldehyde-3-phosphate dehydrogenase gene $(G A P D H)$. The primer pair sets used were the following $\left(5^{\prime} \rightarrow 3^{\prime}\right)$ : Bcl-2 forward, ATG CCT TTG TGG AAC TAT ATG GC, and reverse, GGT ATG CAC CCA GAG TGA TGC; Bcl-xL forward, GCT GGG ACA CTT TTG TGG AT, and 
A

$\mathbf{A}$

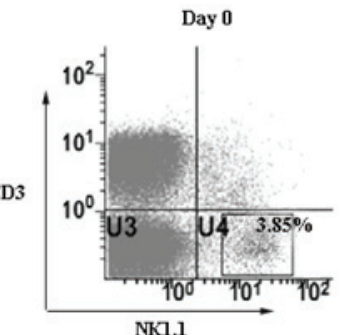

B

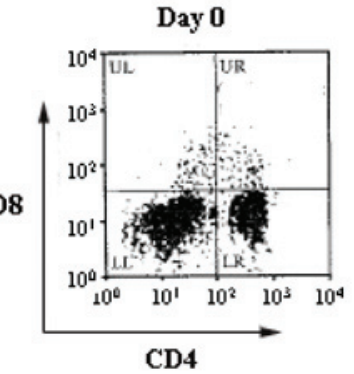

C

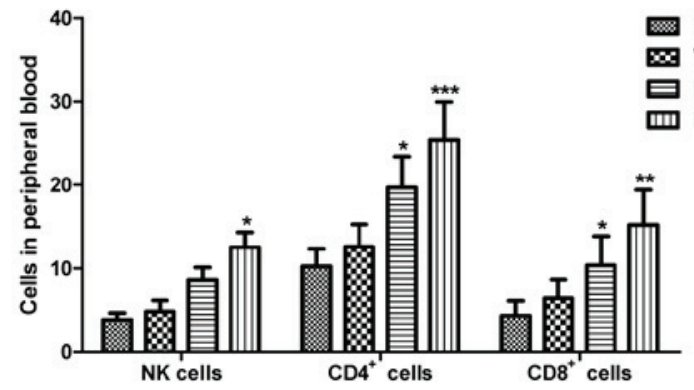

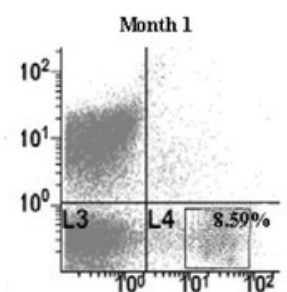
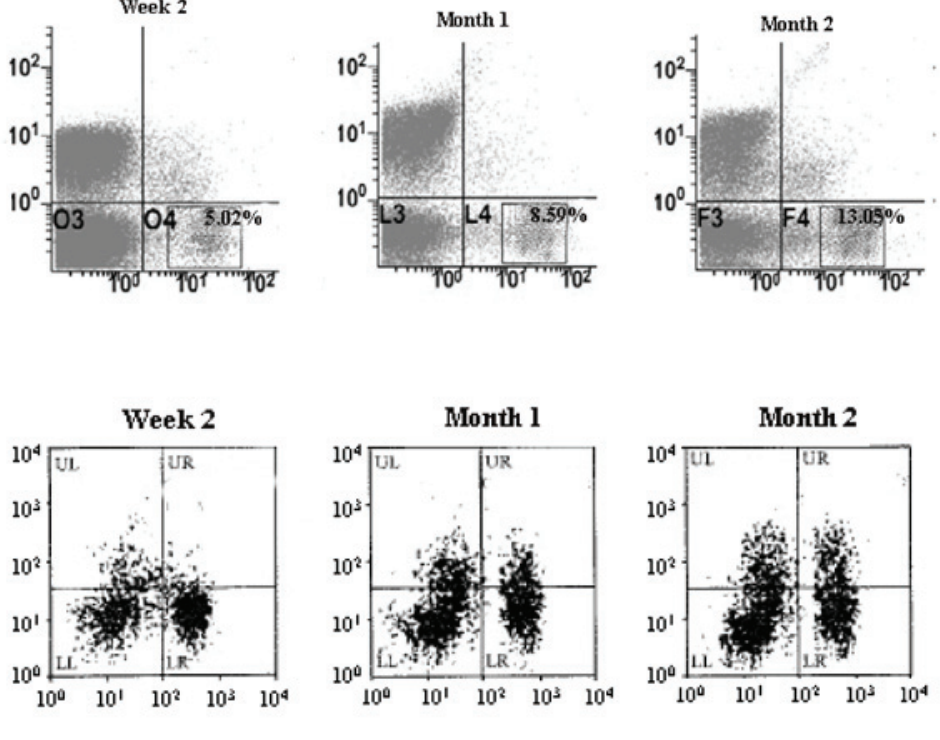

D

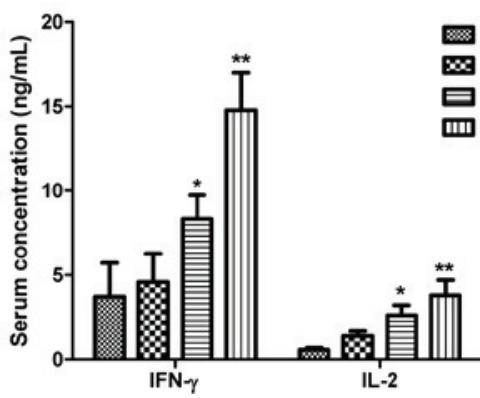

Figure 1. Effects of Kanglaite (KLT) on the relative percentages of host lymphocyte subgroups in the blood and on serum cytokine profiles. (A-C) The percentages of natural killer $(\mathrm{NK}), \mathrm{CD} 4^{+} \mathrm{T}$ and $\mathrm{CD} 8^{+} \mathrm{T}$ cells in the peripheral blood of hepatocellular carcinoma (HCC) patients were determined by flow cytometry analysis (FACS). (D) The concentrations of interferon (IFN)- $\gamma$ and interleukin (IL)-2 in the serum of HCC patients treated with KLT were determined by enzyme-linked immunosorbent assay (ELISA). ${ }^{*} \mathrm{P}<0.05,{ }^{* *} \mathrm{P}<0.01$ and ${ }^{* * *} \mathrm{P}<0.001$ compared with day 0 .

reverse, CTA GGC CCA ACC CTG TGA TA; IL-2 forward, TGA GCA GGA TGG AGA ATT ACA GG, and reverse, ATG TGT TGT CAG AGC CCT TTA G; GAPDH forward, GCA GTG GCA AAG TGG AGA TT, and reverse, GGA GAC AAC CTG GTC CTC AG.

Chromatin immunoprecipitation (ChIP) assay. ChIP assay was performed using polyclonal rabbit anti-p65 antibody purchased from Santa Cruz Biotechnology Inc., (Santa Cruz, CA, USA). ChIP assay was performed using a ChIP assay kit according to the manufacturer's instructions (Millipore, Darmstadt, Germany).

Statistical analysis. Continuous data are expressed as the mean \pm standard error. Comparisons were made using unpaired, two-tailed Student's t-test or one-way analysis of variance. All statistical analyses were conducted using SPSS 16.0 (SPSS, Inc., Chicago, IL, USA).

\section{Results}

Effects of KLT on host lymphocyte subgroups in the blood and on serum cytokine profiles. Following treatment of HCC patients with KLT, we examined the number of T and NK cells in the peripheral blood at week 2, and months 1 and 2. As shown in Fig. 1A-C, KLT treatment increased the number of NK cells $\left(\mathrm{CD}^{+}\right.$and $\left.\mathrm{NK} 1.1^{+}\right)$, as well as that of T cells $\left(\mathrm{CD} 4^{+}\right.$ and $\mathrm{CD}^{+}$) in a time-dependent manner. The IFN- $\gamma$ and IL-2 proteins function as stimulators of immune responses. We evaluated the effect of KLT treatment on the serum profile of these two cytokines. The concentration of serum IFN- $\gamma$ and IL-2 was also time-dependently increased upon KLT treatment in HCC patients (Fig. 1D).

Effects of KLT on growth of the inoculated tumor. To confirm the in vivo anti-HCC effects of KLT, we tested tumor-suppressing activity of KLT at different doses, using cisplatin, a conventional chemotherapeutic drug, as a positive control. The results showed that transplantation of HepG2 cells significantly reduced the body weight of mice (Fig. 2A) while the area of tumors gradually increased (Fig. 2B). The area of tumors was significantly decreased in the KLT high group (treated with $12.5 \mathrm{mg} / \mathrm{kg} \mathrm{KLT}$ ) compared with the group treated with saline (Fig. 2B), without significantly affecting the body weight (Fig. 2A). Treatment with both doses of KLT also significantly reduced the tumor weight $(\mathrm{P}<0.01)$ compared with saline treatment (Table I). By contrast, although cisplatin administration was associated with a higher tumor growth 
A

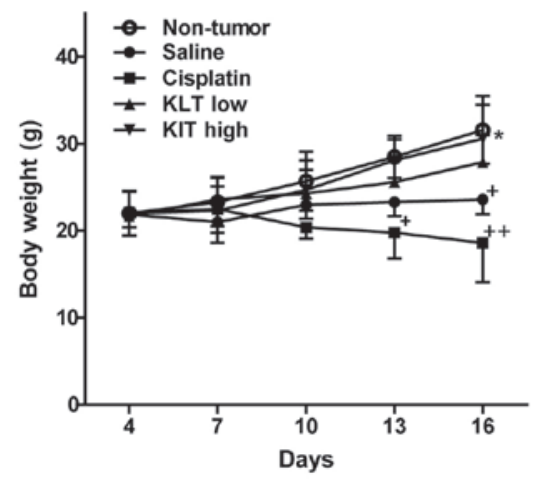

B

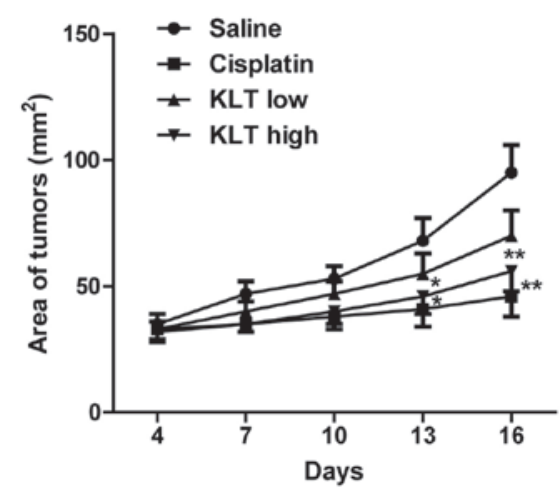

Figure 2. Effects of Kanglaite (KLT) on growth of the HepG2 cell-transplanted tumor in nude mice. Mice were subcutaneously injected with 5x10 ${ }^{6} \mathrm{HepG} 2$ cells. (A) Body weight of the mice was measured every 3 days. (B) Tumor growth was assessed every 3 days by measuring the tumor area. ${ }^{+} \mathrm{P}<0.05$ and ${ }^{++} \mathrm{P}<0.01$, compared with non-tumor mice; ${ }^{*} \mathrm{P}<0.05$ and ${ }^{* *} \mathrm{P}<0.01$, compared with saline treatment.

Table I. Inhibitory effects of KLT on growth of HCC.

\begin{tabular}{llccc}
\hline Group & \multicolumn{1}{c}{$\mathrm{N}$} & $\begin{array}{c}\text { Dose } \\
(\mathrm{mg} / \mathrm{kg})\end{array}$ & $\begin{array}{c}\text { Tumor } \\
\text { weight }(\mathrm{g})\end{array}$ & $\begin{array}{c}\text { Tumor growth } \\
\text { inhibition rate \% }\end{array}$ \\
\hline Non-tumor & $10 / 10$ & - & - & - \\
Saline & $10 / 10$ & - & $1.71 \pm 0.37$ & - \\
Cisplatin & $10 / 7$ & 5 & $0.79 \pm 0.41^{\mathrm{b}}$ & 53.8 \\
KLT low & $10 / 10$ & 6.25 & $1.19 \pm 0.50^{\mathrm{a}}$ & 30.4 \\
KLT high & $10 / 10$ & 12.5 & $1.15 \pm 0.31^{\mathrm{a}}$ & 49.7 \\
\hline
\end{tabular}

KLT, Kanglaite; HCC, hepatocellular carcinoma. ${ }^{\mathrm{a}} \mathrm{P}<0.01$ and ${ }^{\mathrm{b}} \mathrm{P}<0.001$, compared with saline-treated mice. $\mathrm{N}$, the number of mice in each group from the start to the end of the experiment.

Table II. Effects of KLT on serum indexes of liver function.

\begin{tabular}{lccc}
\hline Group & $\begin{array}{c}\text { Dose } \\
(\mathrm{mg} / \mathrm{kg})\end{array}$ & $\begin{array}{c}\text { ALT } \\
(\mathrm{U} / \mathrm{l})\end{array}$ & $\begin{array}{c}\text { AST } \\
(\mathrm{U} / \mathrm{l})\end{array}$ \\
\hline Non-tumor & - & $127.8 \pm 12.3$ & $478.4 \pm 27.9$ \\
Saline & - & $124.6 \pm 10.3$ & $473.2 \pm 25.5$ \\
Cisplatin & 5 & $312.4 \pm 23.4^{\mathrm{a}}$ & $796.4 \pm 23.1^{\mathrm{a}}$ \\
KLT low & 6.25 & $119.0 \pm 11.5$ & $483.8 \pm 21.6$ \\
KLT high & 12.5 & $115.7 \pm 13.7$ & $468.5 \pm 26.7$ \\
\hline
\end{tabular}

KLT, Kanglaite; ALT, alanine aminotransferase; AST, aminotransferase. ${ }^{\text {aP }}<0.01$, compared with non-tumor mice.

inhibitory rate compared with KLT, the average tumor weight in the cisplatin group was significantly decreased $(\mathrm{P}<0.05)$ compared with saline treatment.

Effects of KLT on liver function. A vital aim of cancer chemotherapy is to repress the growth of malignant cells without affecting their normal counterparts. To evaluate the toxicological effects of KLT injection on normal hepatocytes, we measured the serum levels of hepatic function markers i.e.,
A

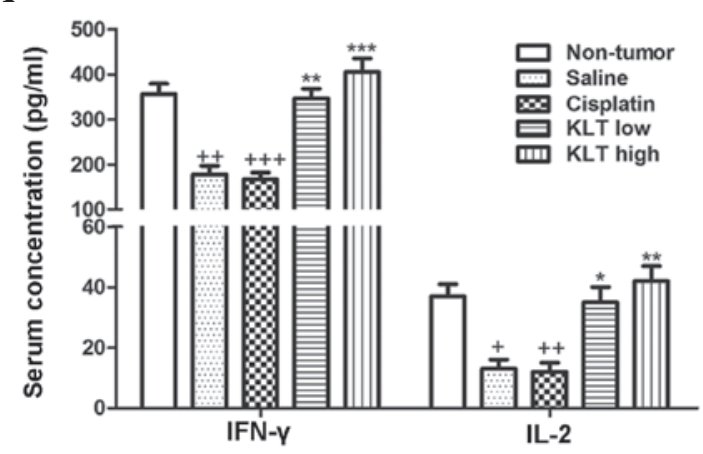

B

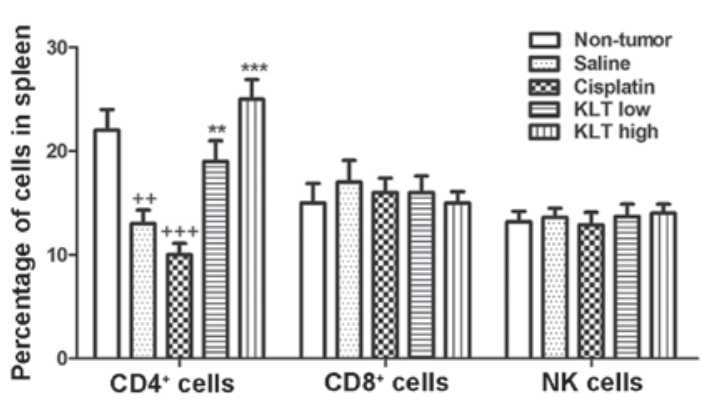

Figure 3. Effects of Kanglaite (KLT) on serum cytokine profiles and spleen lymphocyte subgroup percentages in tumor-bearing mice. Following a 12-day treatment, mice were sacrificed, and the blood samples were collected. (A) Concentrations of interferon ( IFN) $-\gamma$ and interleukin (IL)-2 in the serum of host mice were determined by enzyme-linked immunosorbent assay (ELISA). Spleens were dissected and their single-cell suspensions were prepared. (B) The percentages of $\mathrm{CD}^{+} \mathrm{T}, \mathrm{CD}^{+} \mathrm{T}$ and natural killer (NK) cells in mice spleens were determined by flow cytometry analysis (FACS). ${ }^{+} \mathrm{P}<0.05,{ }^{++} \mathrm{P}<0.01$ and ${ }^{+++} \mathrm{P}<0.001$, compared with non-tumor mice; ${ }^{*} \mathrm{P}<0.05$, ${ }^{* * *} \mathrm{P}<0.01$ and ${ }^{* * *} \mathrm{P}<0.001$, compared with saline treatment.

the activities of ALT and AST. Cisplatin treatment significantly increased the levels of serum ALT and AST $(\mathrm{P}<0.01)$ compared with the non-tumor group, but these two indexes were not clearly affected by KLT injection (Table II).

Effects of KLT on lymphocyte homeostasis and cytokine profiles in mice spleens. As shown in Fig. 3A, transplantation of HepG2 cells reduced the concentrations of IFN- $\gamma$ and IL-2 


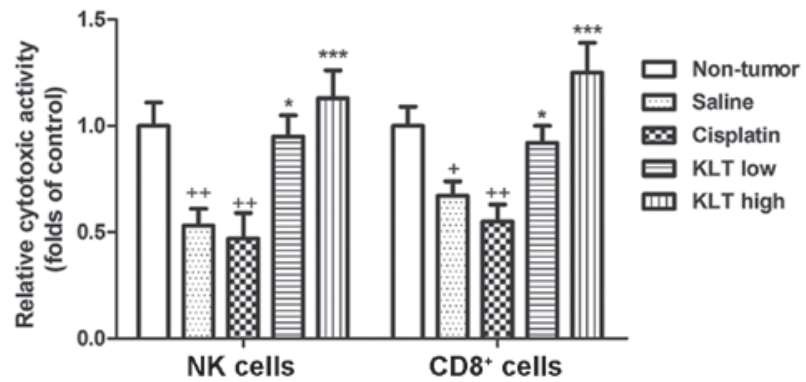

Figure 4. Kanglaite (KLT) enhances the cytotoxic activity of natural killer (NK) and $\mathrm{CD}^{+}{ }^{+} \mathrm{T}$ cells. Following KLT treatment, $\mathrm{NK}$ and $\mathrm{CD} 8^{+} \mathrm{T}$ cells were isolated from the spleen of the mice. The cytotoxic activities of NK and $\mathrm{CD}^{+} \mathrm{T}$ cells against HepG2 cells were determined in a mouse not treated with drugs. ${ }^{+} \mathrm{P}<0.05$ and ${ }^{++} \mathrm{P}<0.01$, compared with non-tumor mice; ${ }^{*} \mathrm{P}<0.05$ and ${ }^{* * *} \mathrm{P}<0.001$, compared with saline treatment.

in the serum $(\mathrm{P}<0.01$ and $\mathrm{P}<0.05$, compared with non-tumor mice), indicating that systemic immunosuppression occurs upon transplantation. Following KLT injection, the serum levels of IFN- $\gamma$ and IL-2 in tumor-bearing mice were significantly higher than those in the saline-treated tumor-bearing mice. However, cisplatin treatment failed to reverse the reduced IFN- $\gamma$ and IL-2 levels in tumor-bearing mice (Fig. 3A). These results suggested that KLT treatment has the potential to alleviate tumor transplantation-induced cytokine dysregulation.

FACS assessment of the percentages of $C D 4^{+} T, C D 8^{+} T$ and NK cells in single-cell suspensions of mice spleens. The results of FACS analysis showed that the percentages of $\mathrm{CD} 8^{+} \mathrm{T}$ and NK cells remained almost unchanged in all experimental groups (Fig. 3B). By contrast, as shown in Fig. 3B, the percentage of $\mathrm{CD}^{+} \mathrm{T}$ cells in the spleen was significantly reduced in the tumor-bearing mice treated with saline as compared with their non-tumor counterparts $(\mathrm{P}<0.01)$. This effect was reversed upon KLT injection $(\mathrm{P}<0.01$ and $\mathrm{P}<0.001$ for the two KLT-treated groups as compared with the saline group, respectively). Cisplatin treatment did not reverse the tumor transplantation-induced reduction in the $\mathrm{CD}^{+} \mathrm{T}$ cell percentage (Fig. 3B).

KLT enhances the cytotoxic activity of $\mathrm{NK}$ and $\mathrm{CD} 8^{+} \mathrm{T}$ cells against HepG2 cells. $\mathrm{CD} 4^{+} \mathrm{T}$ cells can mediate antitumor responses by stimulating the cytotoxic activity of NK and $\mathrm{CD} 8^{+} \mathrm{T}$ cells. We therefore determined the effects of KLT treatment on the cytotoxic activities of $\mathrm{NK}$ and $\mathrm{CD} 8^{+} \mathrm{T}$ cells against HepG2 cells. As shown in Fig. 4, HepG2 tumor cell transplantation markedly reduced the cytotoxic activities of $\mathrm{NK}$ and $\mathrm{CD} 8^{+} \mathrm{T}$ cells as compared with the non-tumor control group $(\mathrm{P}<0.01$ and $\mathrm{P}<0.05$, respectively). Cisplatin treatment also significantly $(\mathrm{P}<0.01)$ reduced the cytotoxic activities of NK cells and $\mathrm{CD}^{+} \mathrm{T}$ cells (Fig. 4). By contrast, KLT treatment increased the cytotoxic activities of these cells $(\mathrm{p}<0.05$ in the low-dose group and $\mathrm{P}<0.001$ in the high-dose group) compared with the saline-treated group.

KLT activates $N F-\kappa B$ signaling in $C D 4^{+} T$ cells. NF- $\kappa \mathrm{B}$ is a pivotal transcription factor that both promotes cell survival and stimulates immune response. Therefore, we tested whether KLT activates NF- $\kappa B$ signaling in the $\mathrm{CD} 4^{+} \mathrm{T}$ cells of
A

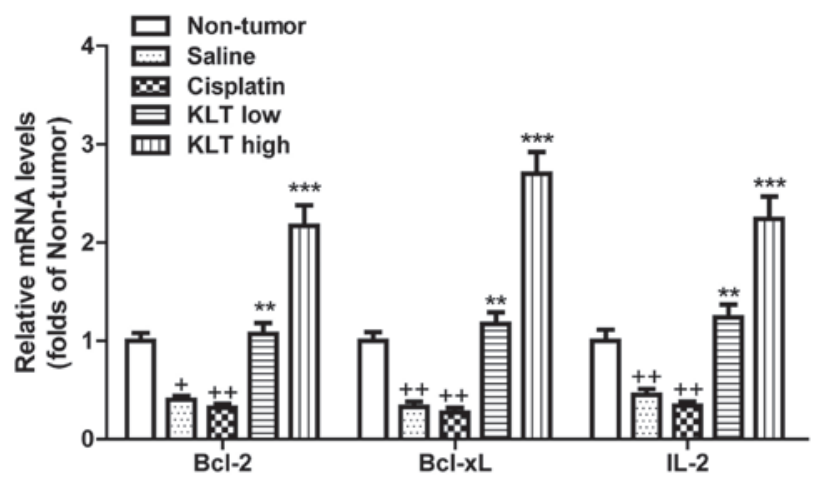

B

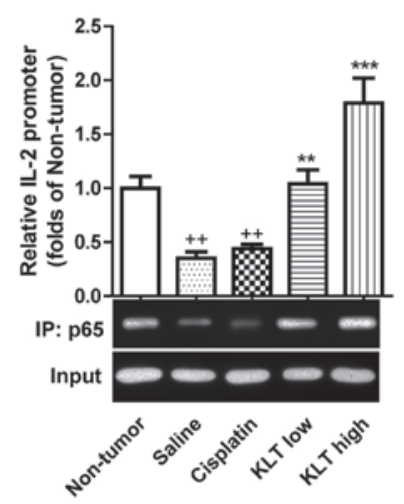

C

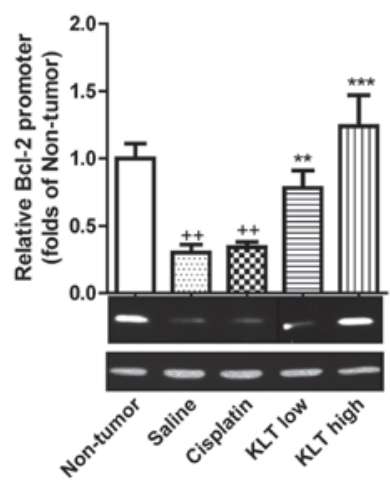

Figure 5. Kanglaite (KLT) activates nuclear factor $\kappa \mathrm{B}(\mathrm{NF}-\kappa \mathrm{B})$ signaling in the $\mathrm{CD}^{+} \mathrm{T}$ cells of the host. (A) The levels of the genes B-cell lymphoma-2 (Bcl-2), Bcl- $x L$ and interleukin-2 $(I L-2)$ in spleen $C D 4^{+} \mathrm{T}$ cells from tumor-bearing mice were determined by quantitative reverse transcription-PCR, using the glyceraldehyde-3-phosphate dehydrogenase gene as a control. Isolated $\mathrm{CD}^{+} \mathrm{T}$ cells were subjected to the chromatin immunoprecipitation (ChIP) assay using an antibody targeting the NF- $\kappa \mathrm{B}$ p65 subunit. The precipitated DNA was analyzed by quantitative PCR using sets of primers specific to (B) IL-2 and (C) Bcl-2 promoters followed by agarose gel electrophoresis. ${ }^{+} \mathrm{P}<0.05$ and ${ }^{++} \mathrm{P}<0.01$, compared with non-tumor mice; ${ }^{* *} \mathrm{P}<0.01$ and ${ }^{* * *} \mathrm{P}<0.001$, compared with saline treatment.

tumor-bearing mice. We examined the effects of KLT injection on the transcriptional level of a subset of NF-kB-regulated genes, $B c l-2, B c l-x L$ and $I L-2$ In $C D 4^{+} \mathrm{T}$ cells. HepG2 tumor cell transplantation markedly reduced the transcription of these NF- $\mathrm{BB}$-responsive genes $(\mathrm{P}<0.05$ for $B c \mathrm{l}-2$ and $\mathrm{P}<0.01$ for $B c l-x L$ and $I L-2$ compared with the non-tumor group). The levels of $B c l-2, B c l-x L$ and $I L-2$ were significantly increased by KLT treatment $(\mathrm{P}<0.01$ in the low-dose group and $\mathrm{P}<0.001$ in the high-dose group) compared with saline treatment (Fig. 5A). 
By contrast, cisplatin treatment did not reverse the reduction in $B c l-2, B c l-x L$ and $I L-2$ levels induced by the tumor transplantation (Fig. 5A). Additionally, the ChIP assay demonstrated that following ALT treatment, more NF- $\mathrm{B}$ p 65 proteins associated with the promoter regions of IL-2 and Bcl-2 encoding genes in $\mathrm{CD}^{+} \mathrm{T}$ cells (Fig. 5B and C). Collectively, these results suggested that KLT activates part of $N F-\kappa B$ signaling in $\mathrm{CD}^{+} \mathrm{T}$ cells of the host.

\section{Discussion}

Herbal products are used in traditional medicine for the prevention or treatment of cancer in various societies worldwide. Since one of the most important adverse effects of chemotherapeutic drugs is the reduced immunity of the patients, it is highly desirable to treat patients with drugs that not only exert antitumor effects, but also enhance their immunity $(18,19)$. A previous study demonstrated the antitumor activity and immunomodulatory effects of KLT in vivo, using mice with Lewis lung carcinoma (14). Our study also indicated that KLT treatment may enhance the immune system of patients with HCC. The present study also demonstrated that KLT significantly inhibits tumor growth in mice transplanted with HepG2 cells. KLT increased the percentage of $\mathrm{CD}^{+} \mathrm{T}$ cells, the serum concentrations of IFN- $\gamma$ and IL-2, and the cytotoxic activity of $\mathrm{NK}$ and $\mathrm{CD}^{+} \mathrm{T}$ cells against HepG2 cells. Furthermore, KLT increased the expression of the NF- $\kappa \mathrm{B}$-responsive genes $B c l-2, B c l-x L$ and $I L-2$ in $\mathrm{CD}^{+}{ }^{+} \mathrm{T}$ cells. Cisplatin did not enhance the immune system (IFN- $\gamma$ and IL-2 levels, spleen lymphocyte subgroup percentages) and did not rescue the expression of $B c l-2, B c l-x L$ and $I L-2$ in the mouse model of HCC. Liver function indexes, i.e., the activities of ALT and AST, were the only features that were significantly improved by cisplatin in contrast to KLT treatment. Overall, although KLT showed a reduced antitumor activity (tumor growth inhibition rate, tumor weight) compared with cisplatin, it had an apparent advantage in enhancing the patients' immunity in our experiments.

Natural regulatory $\mathrm{T}$ cells are present in high frequencies in tumor-infiltrating lymphocytes and in draining lymph nodes, and are thought to facilitate tumor development. $\mathrm{CD}^{+} \mathrm{T}$ cells are a key subset of immune cells mediating antitumor immune defense $(20,21)$. It has been demonstrated that cancer cells can induce $\mathrm{CD}^{+} \mathrm{T}$ cell apoptosis, which contributes to immune evasion during tumor progression $(22,23)$. Consistent with these reports, we found that following transplantation of the hepatic HepG2 tumor cells, the percentage of $\mathrm{CD}^{+} \mathrm{T}$ cells, but not $\mathrm{CD}^{+} \mathrm{T}$ or NK cells, was decreased in the spleen. KLT administration alleviated the tumor cell transplantation-induced reduction of $\mathrm{CD}^{+} \mathrm{T}$ cell percentage, which suggests that KLT has the potential to ameliorate tumor-induced immunodeficiency. T helper 1 (Th1) cells, a subtype of $\mathrm{CD}^{+} \mathrm{T}$ cells, were shown to secrete the IFN- $\gamma$ and IL-2 cytokines (22), which improve the cytotoxicity of $\mathrm{CD} 8^{+} \mathrm{T}$ and $\mathrm{NK}$ cells and promote antitumor immune responses $(24,25)$. Similarly in this study, we showed that following transplantation of HepG2 tumor cells, the serum levels of the Th1 cytokines IFN- $\gamma$ and IL-2 were decreased. The cytotoxic activities of $\mathrm{CD}^{+} \mathrm{T}$ and $\mathrm{NK}$ cells against HepG2 cells were also impaired. KLT treatment significantly increased the cytotoxic activity of both NK cells and $\mathrm{CD}^{+} \mathrm{T}$ cells against HepG2 cells. These events rescue the systemic immunosuppression induced by tumor transplantation and stimulate the host anticancer immune response, which may explain the in vivo KLT anticancer activity.

$N F-\kappa B$ is crucial for the regulation of numerous biological processes, including cell apoptosis and immune response. $\mathrm{NF}-\kappa \mathrm{B}$ signaling inhibits cell apoptosis by inducing the transcription of various anti-apoptotic genes, such as $\mathrm{Bcl}-2$ and $B c l-x L$ (26). The expression of Bcl-2 was demonstrated to play a pivotal role in the control of $\mathrm{CD}^{+} \mathrm{T}$ cell survival (27). Moreover, the induction, by $\mathrm{NF}-\kappa \mathrm{B}$, of the transcription of the $I F N-\gamma$ and $I L-2$ genes, which modulate the immune response, is well established (28). In line with the inhibitory effect of $\mathrm{NF}-\kappa \mathrm{B}$ previously reported, we found that KLT increases the serum levels of IFN- $\gamma$ and IL-2. We also assessed the effects of KLT on the transcription of the NF- $\kappa \mathrm{B}$-responsive genes Bcl-2, Bcl-xL and $I L-2$ by qRT-PCR. Consistently, our ChIP assay revealed that KLT administration increased the interaction between the NF- $\mathrm{B}$ p 65 subunit and the promoter regions of $\mathrm{Bcl}-2$ and IL-2 encoding genes in $\mathrm{CD}^{+} \mathrm{T}$ cells. The results demonstrated that KLT treatment upregulates these genes in $\mathrm{CD}^{+} \mathrm{T}$ cells of tumor-bearing mice.

Notably, KLT treatment did not affect the percentage of $\mathrm{CD}^{+} \mathrm{T}$ cells or the transcription of NF- $\kappa \mathrm{B}$-regulated genes in these cells (data not shown). This observation suggests that KLT selectively activates NF- $\kappa \mathrm{B}$ signaling in $\mathrm{CD}^{+} \mathrm{T}$ cells. The unique gene expression pattern observed in $\mathrm{CD}^{+} \mathrm{T}$ cells may contribute to the cell-type specificity of KLT, although the underlying molecular mechanisms deserve further investigation. Collectively, our study provided a molecular basis for the application of coix seed extract in HCC treatment. In addition, our data support a future clinical use of KLT as an adjuvant reagent that stimulates anticancer immune responses in patients with $\mathrm{HCC}$.

\section{Acknowledgements}

This study was supported by the research grant P200901 from the Medical Science and Technology Development Fund of the Health Bureau of Jiangsu Province.

\section{References}

1. Nordenstedt H, White DL and El-Serag HB: The changing pattern of epidemiology in hepatocellular carcinoma. Dig Liver Dis 42 (Suppl 3): S206-S214, 2010.

2. Clavien PA, Petrowsky H, DeOliveira ML and Graf R: Strategies for safer liver surgery and partial liver transplantation. N Engl J Med 356: 1545-1559, 2007.

3. Brunocilla PR, Brunello F, Carucci P, et al: Sorafenib in hepatocellular carcinoma: prospective study on adverse events, quality of life, and related feasibility under daily conditions. Med Oncol 30: 345, 2013.

4. Pawlik TM, Reyes DK, Cosgrove D, Kamel IR, Bhagat N and Geschwind JF: Phase II trial of sorafenib combined with concurrent transarterial chemoembolization with drug-eluting beads for hepatocellular carcinoma. J Clin Oncol 29: 3960-3967, 2011.

5. Vasievich EA and Huang L: The suppressive tumor microenvironment: a challenge in cancer immunotherapy. Mol Pharm 8: 635-641, 2011.

6. Pardee AD and Butterfield LH: Immunotherapy of hepatocellular carcinoma: unique challenges and clinical opportunities. Oncoimmunology 1: 48-55, 2012. 
7. Ormandy LA, Farber A, Cantz T, et al: Direct ex vivo analysis of dendritic cells in patients with hepatocellular carcinoma. World J Gastroenterol 12: 3275-3282, 2006.

8. Hoechst B, Voigtlaender T, Ormandy L, et al: Myeloid derived suppressor cells inhibit natural killer cells in patients with hepatocellular carcinoma via the NKp30 receptor. Hepatology 50: 799-807, 2009.

9. Teitz-Tennenbaum S, Li Q, Okuyama R, et al: Mechanisms involved in radiation enhancement of intratumoral dendritic cell therapy. J Immunother 31: 345-358, 2008.

10. Krusch M, Salih J, Schlicke M, et al: The kinase inhibitors sunitinib and sorafenib differentially affect NK cell antitumor reactivity in vitro. J Immunol 183: 8286-8294, 2009.

11. Zhang QB, Sun HC, Zhang KZ, et al: Suppression of natural killer cells by sorafenib contributes to prometastatic effects in hepatocellular carcinoma. PLoS One 8: e55945, 2013.

12. Lu Y, Li CS and Dong Q: Chinese herb related molecules of cancer-cell-apoptosis: a minireview of progress between Kanglaite injection and related genes. J Exp Clin Cancer Res 27: 31, 2008

13. Zhan YP, Huang XE, Cao J, et al: Clinical safety and efficacy of Kanglaite ${ }^{\circledR}$ (Coix Seed Oil) injection combined with chemotherapy in treating patients with gastric cancer. Asian Pac J Cancer Prev 13: 5319-5321, 2012.

14. Pan P, Wu Y, Guo ZY, Wang R, Wang YJ and Yuan YF: Antitumor activity and immunomodulatory effects of the intraperitoneal administration of Kanglaite in vivo in Lewis lung carcinoma. J Ethnopharmacol 143: 680-685, 2012.

15. Wullaert A, Bonnet MC and Pasparakis M: NF- $\kappa B$ in the regulation of epithelial homeostasis and inflammation. Cell Res 21 146-158, 2011

16. Porta C, Larghi P, Rimoldi M, et al: Cellular and molecular pathways linking inflammation and cancer. Immunobiology 214 761-777, 2009

17. Zhang Y, Yu G, Wang D, Hu Y and Lei W: ERK1/2 activation plays important roles in the opposite effects of Trichostatin A in non-cancer and cancer cells. Toxicon 57: 932-937, 2011.
18. Lee S, Ra J, Song JY, et al: Extracts from Citrus unshiu promote immune-mediated inhibition of tumor growth in a murine renal cell carcinoma model. J Ethnopharmacol 133: 973-979, 2011.

19. Wang J, Tong X, Li P, Cao H and Su W: Immuno-enhancement effects of shenqi fuzheng injection on cyclophosphamide-induced immunosuppression in Balb/c mice. J Ethnopharmacol 139: 788-795, 2012

20. Huang H, Hao S, Li F, Ye Z, Yang J and Xiang J: CD4+ Th1 cells promote $\mathrm{CD} 8+\mathrm{Tc} 1$ cell survival, memory response, tumor localization and therapy by targeted delivery of interleukin 2 via acquired pMHC I complexes. Immunology 120: 148-159, 2007.

21. Rakhra K, Bachireddy P, Zabuawala T, et al: $\mathrm{CD}^{+}{ }^{+} \mathrm{T}$ cells contribute to the remodeling of the microenvironment required for sustained tumor regression upon oncogene inactivation. Cancer Cell 18: 485-498, 2010.

22. Chaput N, Darrasse-Jeze G, Bergot AS, et al: Regulatory T cells prevent CD8 T cell maturation by inhibiting CD4 Th cells at tumor sites. J Immunol 179: 4969-4978, 2007.

23. Biswas K, Richmond A, Rayman P, et al: GM2 expression in renal cell carcinoma: potential role in tumor-induced T-cell dysfunction. Cancer Res 66: 6816-6825, 2006.

24. Cui G and Florholmen J: Polarization of cytokine profile from Th1 into Th2 along colorectal adenoma-carcinoma sequence: implications for the biotherapeutic target? Inflamm Allergy Drug Targets 7: 94-97, 2008.

25. Grimm M, Gasser M, Bueter M, et al: Evaluation of immunological escape mechanisms in a mouse model of colorectal liver metastases. BMC Cancer 10: 82, 2010.

26. Baldwin AS: Regulation of cell death and autophagy by IKK and NF- $\mathrm{KB}$ : critical mechanisms in immune function and cancer. Immunol Rev 246: 327-345, 2012.

27. Shi Y, Feng Y, Kang J, et al: Critical regulation of $\mathrm{CD}^{+}{ }^{+} \mathrm{T}$ cell survival and autoimmunity by $\beta$-arrestin 1 . Nat Immunol 8: 817-824, 2007.

28. Weil R and Israel A: T-cell-receptor- and B-cell-receptor-mediated activation of NF-kappaB in lymphocytes. Curr Opin Immunol 16: 374-381, 2004. 